\title{
MANAGEMENT OPTIONS FOR CEREBRAL GLIOMAS
}

\author{
Wael A.A. El-Mesallamy; Hamdy M. Farahat; Tarek H. Abdel Bary and Magdy E.H. Rashed \\ Neurosurgery Department, Faculty of Medicine, Zagazig University
}

\begin{abstract}
Background: Cerebral gliomas are the most prevalent primary brain tumors in adult patients. Objectives: The purpose of this prospective study was evaluation of various management strategies including surgery facilitated by intraoperative ultrasonography, radiotherapy and chemotherapy with addressing impact of various factors on the outcome. Patients and methods: In a prospective evaluation, we studied 55 adult patients with primary cerebral gliomas who were operated upon at our department between January 2009 and January 2011 with follow up at least one year for survived patients. Radiotherapy was received postoperatively by 48 patients of whom 34 patients received chemotherapies. All clinical, radiological, imaging, pathological and management modality records were evaluated as prognostic factors. Results: The mean survival time was 13.7 months. We confirmed that the patient age, preoperative functional status (by Karnofesky scale), location of cerebral gliomas, size of gliomas, extent of resection, intraoperative ultrasonography use, grades of glioma and postoperative functional status as decisive prognostic factors and had an impact on outcome. Conclusion: We could show that young ages ( $\geq 16-40$ years), high preoperative Karnofesky scores $(\geq 80 \%)$, single-lobe involvement by glioma, small tumor size $(\leq 5 \mathrm{~cm})$, gross total resection, intraoperative ultrasonography use, low-grade gliomas and high postoperative Karnofesky scores $(\geq 80 \%)$ were predictors for better outcome.
\end{abstract}

Keywords: cerebral glioma, survival, prognosis, outcome, intraoperative ultrasound

\section{INTRODUCTION}

G lial tumors are the most common types of primary brain neoplasms and constitute approximately $60 \%$ of all primary brain tumors ${ }^{(1)}$.

There are three standard types of treatment for patients with glioma: surgery, radiation therapy and chemotherapy. Major centers may offer experimental treatments, while therapies for high grade gliomas are helpful. At present, these treatments cannot cure the tumors ${ }^{(2)}$.

The tumor mass evaluated with the help of ultrasonography enhancing the surgeon feeling of safety and leading to greater confidence that the lesion was excised as completely as possible without disturbing adjacent viable tissue and thus avoiding new postoperative neurological deficits $^{(3)}$.

Several variables affect prognosis and therapy options of patients with cerebral gliomas as patient age, performance status, extent of resection, tumor size, tumor location, tumor grades, tumor biology and adjuvant therapies ${ }^{(\mathbf{4})}$.

The aim of this study is evaluation of the results of various management strategies of adult patients with primary cerebral gliomas including surgery facilitated by intraoperative ultrasonography, radiotherapy and chemotherapy with addressing impact of the various factors on the outcome.

\section{PATIENTS AND METHODS}

A prospective study of 55 adult patients with cerebral glioma operated upon at Neurosurgery Department, Faculty of Medicine, Zagazig University between January 2009 to January 2011.

Patients with recurrent glioma, intraventricular glioma and ages $<16$ years were excluded from this study. All patients were subjected to clinical, laboratory, radiological and imaging investigations before surgery under general anaesthesia for surgical resection.

Intraoperative ultrasonography was used during surgeries of 25 patients. RIBE-2500D digital ultrasound scanner with $5-8 \mathrm{MHz}$ endocavitary probe was used for 15 patients and EUB-405 plus ultrasound scanner with $3-10 \mathrm{MHz}$ convex probe was used for 10 patients. The probe was covered by a sterile glove and the ultrasound gel put inside the glove. The probe was used on the dura and then on the brain and the tumor to visualize the tumor location, characters, nearby brain landmarks, and resection monitoring. The real time mode was used and then the B-mode for doing the measurements, we firstly adjust the gain button which determines the grey-white compensation curve. So, the normal brain tissue is uniformly hypoechoic.

Postoperative assessment for the patients was done clinically and CT or MRI brain was done within 48 hours postoperatively for assessment of extent of resection and detection of surgical complications.

The extent of resection based on operative records and postoperative CT or MRI finding. Gross total resection was defined if the mass was removed totally. However, a subtotal resection was defined if $\geq 50 \%$ resection and partial resection if $<50 \%$ resection achieved.

Radiotherapy was given either by linear accelerator or cobalt machines for high grade glioma in dose of 60-65 Grays and for low grade glioma in dose of 54 Grays. Fractionation regimen used was 1.8-2 Grays/fraction for five days/week. 
There were 48 patients treated postoperatively by radiotherapy.

The patients treated by chemotherapy divided into two groups; one received temozolamide (13 patients) and the another group received PCV regimen [Procarbazine, CCNU (Lomustin) and Vincristine] (21 patients).

Follow up of the patients was done for at least one year for survived patients. The frequencies of follow up were one week after hospital discharge, every one month during first 6 months and then every 3 months. Follow up was done if the patient complained at any time. During follow up, the patients subjected to CT brain or MRI brain especially at the end of adjuvant therapies and when the patient developed neurological manifestations.

The functional status was evaluated according to Karnofesky scale ${ }^{(5)}$.

Patients with Karnofesky rating $\geq 80$ were graded as independent, patients with rating 60-70 were graded as semidependent and patients with rating $\leq 50$ were considered dependent ${ }^{(6)}$.

All clinical, radiological, imaging, pathological and management modality records were evaluated as prognostic factors.

\section{Statistical analysis:}

Data were checked, tabulated and analyzed by using SPSS version 19. Data were expressed as mean for quantitative variable numbers and percentages for categorical variables. Chi-square, Fisher exact and student $t$ tests were used when appropriate. $\mathrm{p}<0.05$ was considered statistically significant. Survival (till time of death) and tumor recurrence (progression-free survival) were measured from the date of surgery.

\section{RESULTS}

In table 1 , the ages of the patients ranged from 17 to 77 years, the mean age was 43 years and the commonest age group was 30-40 years. There were 36 males (65.5\%) and 19 females $(34.5 \%)$ with male to female of 1.9:1. Gradual onset of symptoms was found in $65.5 \%$ of the patients, while acute onset by fits was found in $34.5 \%$,progressive course was found in $78 \%$ and remission and exacerbation of only fits was found in $22 \%$ of the patients. The duration of symptoms ranged from 3 weeks to 8 years with mean of 11.4 months. The commonest symptom was headache in $78.2 \%$ of the patients and the commonest sign was papilloedema in $67.3 \%$. Frontal lobe location was the predominant in $62.1 \%$ and tumor size $\leq 5$ $\mathrm{cm}$ was found in $52.7 \%$.

Pathological types were glioblastoma (WHO GIV) in 21 patients, anaplastic astrocytoma (GIII) in 15 patients, astrocytoma
(GII) in 11 patients, pleomorphic xanthoastrocytoma (GII) in 3 patients, pilocytic astrocytoma (GI) in 2 patients, subependymal giant cell astrocytoma (GI) in one patient and mixed glioma in 2 patients; one with mixed anaplastic astrocytoma and oligodendroglioma (GIII) and one with pilocytic astrocytoma with focal oligodendroglioma (GII).

In table 2, Intraoperative Ultrasonography (IOUS) was used in 25/55 operations for surgical removal of primary cerebral glioma. The comparison with preoperative CT and MRI showed that the ultrasonography delineated the cystic components, necrotic components, calcification and perilesional oedema in all the tumors where present in preoperative investigations with more clearance of these components as there were septae inside some cysts were not clear in preoperative investigations. Tumor edges were more well-defined in ultrasonographic images $(23 / 25,92 \%)$, while well-defined tumor edges in preoperative investigations were $12 / 25,48 \%)(p<0.05$, significant).

In this study, there was significant gross total resection $(\mathrm{p}=0.001)$ in the cases with intraoperative ultrasonography use (figures 1-9) and significant partial resections in the cases without intraoperative ultrasonography use $(\mathrm{p}=$ $0.001)$.

In this study, the operative complications occurred in $19 / 55$ patients $(34.5 \%)$; of them two mortalities $(3.6 \%)$ and 4 patients with major deficits (motor weakness, speech and cognitive deficits). There were no significant difference between the two groups (with IOUS use and without IOUS use) regarding the operative complication, while there were significant differences regarding severe operative complications (including mortalities and major deficits) in favour of use of intraoperative ultrasonography. No operative mortalities were found in IOUS group.

There were significant correlation between IOUS use and independent functional outcome and Karnofesky improvements.

In table 3 , the mean survival was 13.7 months, the median survival was 12.5 months and one-year survival was $38 / 55$ patients $(69.1 \%)$. The operative mortalities (within 30 days after surgery) were $2 / 55$ patients (3.6\%).

By univariate analysis of different factors, in relation to postoperative Karnofesky score improvement, independent functional outcome, progression-free survival (till tumor recurrence) and one-year survival (till patient death), it was 
found that all the variables studied affected the prognosis significantly except sex of the patients, tumor lateralization (right or left), type of lobe involvement (frontal or partial or temporal or occipital) and types of chemotherapy used.

The regression response of residual glioma after surgery to adjuvant therapies occurred in $12 / 34$ patients $(35.3 \%)$. The regression response to radiotherapy and chemotherapy occurred in $6 / 22$ patients $(27.3 \%)$ and to radiotherapy without chemotherapy in $6 / 12$ patients $(50 \%)$; we cannot compare the two groups as radiotherapy with chemotherapy were given mostly to patients with malignant gliomas $(97 \%$ of this group with malignant gliomas), while radiotherapy without chemotherapy was given mostly to patients with benign gliomas $(92.9 \%)$.

In this study, no significant difference between the patients received temozolamide chemotherapy and the patients received PCV chemotherapy regimen regarding regression response $(\mathrm{p}=0.03)$.

Table (1): Characteristics of 55 patients with cerebral gliomas

\begin{tabular}{|c|c|c|}
\hline Patient characteristics & No & $\%$ \\
\hline \multicolumn{3}{|l|}{ Age } \\
\hline$\leq 40$ years & 26 & 47.3 \\
\hline$>40$ years & 29 & 52.7 \\
\hline \multicolumn{3}{|l|}{ Sex } \\
\hline Males & 36 & 65.5 \\
\hline Females & 19 & 34.5 \\
\hline \multicolumn{3}{|l|}{ Onset of symptoms } \\
\hline Gradual & 36 & 65.5 \\
\hline Acute & 19 & 34.5 \\
\hline \multicolumn{3}{|l|}{ Course of symptoms } \\
\hline Progressive & 43 & 78 \\
\hline Remission and exacerbation & 12 & 22 \\
\hline \multicolumn{3}{|l|}{ Commonest symptoms } \\
\hline Headache & 43 & 78.2 \\
\hline Motor weakness & 28 & 51 \\
\hline Epileptic fits & 26 & 47.3 \\
\hline \multicolumn{3}{|l|}{ Commonest signs } \\
\hline Papilloedema & 37 & 67.3 \\
\hline Motor weakness & 28 & 51 \\
\hline \multicolumn{3}{|l|}{ Preoperative Karnofesky scores } \\
\hline $80-90$ & 16 & 29 \\
\hline $60-70$ & 24 & 43.6 \\
\hline$\leq 50$ & 15 & 27.2 \\
\hline \multicolumn{3}{|l|}{ Tumor lateralization } \\
\hline Right & 31 & 56.4 \\
\hline Left & 22 & 40 \\
\hline Bilateral & 2 & 3.6 \\
\hline \multicolumn{3}{|l|}{ Lobe involvement } \\
\hline 3 lobes & 1 & 1.8 \\
\hline 2 lobes & 25 & 45.5 \\
\hline Single lobe & 29 & 52.7 \\
\hline Frontal & 18 & 62.1 \\
\hline Parietal & 8 & 27.6 \\
\hline Temporal & 2 & 6.9 \\
\hline Occipital & 1 & 3.4 \\
\hline \multicolumn{3}{|l|}{ Tumor depth } \\
\hline Cortical & 36 & 65.5 \\
\hline
\end{tabular}




\begin{tabular}{|c|c|c|}
\hline Subcortical & 19 & 34.5 \\
\hline \multicolumn{3}{|l|}{ Tumor size } \\
\hline$\leq 5 \mathrm{~cm}$ & 29 & 52.7 \\
\hline$>5 \mathrm{~cm}$ & 26 & 47.3 \\
\hline \multicolumn{3}{|c|}{ Extent of tumor resection } \\
\hline Gross total & 18 & 32.7 \\
\hline Subtotal & 22 & 40 \\
\hline Partial & 15 & 27.3 \\
\hline \multicolumn{3}{|l|}{ Tumor grades } \\
\hline IV & 21 & 38.2 \\
\hline III & 16 & 29.1 \\
\hline II & 15 & 27.3 \\
\hline $\mathrm{I}$ & 3 & 5.5 \\
\hline \multicolumn{3}{|l|}{ Postoperative Karnofesky score } \\
\hline$\geq 80$ & 30 & 54.5 \\
\hline $60-70$ & 19 & 34.5 \\
\hline$\leq 50$ & 6 & 10.9 \\
\hline
\end{tabular}

Table (2): Intraoperative ultrasonography evaluation

\begin{tabular}{cc}
\hline Comparison items & $\mathbf{p}$ \\
\hline Comparison to preoperative investigations (CT and/or MRI) & \\
\hline Well-defined tumor edges & 0.001 \\
\hline Comparison to the groups without IOUS use & \\
\hline Gross total resection & 0.001 \\
\hline Overall operative complications & $>0.05$ \\
\hline Severe operative complications & 0.046 \\
\hline Postoperative Karnofesky score improvement & 0.001 \\
\hline Postoperative independent functional outcome & 0.02 \\
\hline
\end{tabular}

Table (3): Prognostic factors and results of univariate analysis of studied glioma patients

\begin{tabular}{|c|c|c|c|c|}
\hline Variable & $\begin{array}{c}\text { Karnofesky } \\
\text { improvement } \\
\text { p value }\end{array}$ & $\begin{array}{c}\text { Independent } \\
\text { functional } \\
\text { outcome } \\
\text { p value }\end{array}$ & $\begin{array}{c}\text { Progression- } \\
\text { free survival } \\
\text { p value }\end{array}$ & $\begin{array}{c}\text { One-year } \\
\text { survival } \\
\text { p value }\end{array}$ \\
\hline Age & NS & - & - & - \\
\hline$\geq 16-40$ years & - & 0.015 & 0.001 & 0.02 \\
\hline$>40$ years & - & - & - & - \\
\hline Sex & NS & NS & NS & NS \\
\hline Males & - & - & - & - \\
\hline Females & - & - & - & - \\
\hline $\begin{array}{l}\text { Preoperative } \quad \text { Karnofesky } \\
\text { score }\end{array}$ & - & - & - & - \\
\hline$\geq 80$ & - & 0.001 & 0.002 & 0.006 \\
\hline $60-70$ & - & - & - & - \\
\hline$\leq 50$ & 0.04 & - & - & - \\
\hline Tumor size & - & NS & - & - \\
\hline$\leq 5 \mathrm{~cm}$ & - & - & 0.01 & 0.03 \\
\hline$>5 \mathrm{~cm}$ & - & - & - & - \\
\hline Tumor lateralization & - & $\mathrm{NS}$ & NS & $\mathrm{NS}$ \\
\hline $\begin{array}{l}\text { Number of lobe involvement } \\
\text { by glioma }\end{array}$ & - & - & - & - \\
\hline
\end{tabular}




\begin{tabular}{|c|c|c|c|c|}
\hline 3 lobes & - & - & - & - \\
\hline 2 lobes & - & - & - & - \\
\hline Single & - & 0.001 & 0.04 & 0.04 \\
\hline $\begin{array}{l}\text { Type of lobe involvement by } \\
\text { glioma }\end{array}$ & - & NS & NS & NS \\
\hline Tumor relation to brain depth & - & NS & - & $\mathrm{NS}$ \\
\hline Cortical & - & - & 0.02 & - \\
\hline Subcortical & - & - & - & - \\
\hline Extent of resection & - & - & - & - \\
\hline Gross total & 0.001 & 0.001 & 0.001 & 0.003 \\
\hline Subtotal & - & - & - & - \\
\hline Partial & - & - & - & - \\
\hline $\begin{array}{l}\text { Intraoperative } \\
\text { ultrasonography }\end{array}$ & - & - & NS & NS \\
\hline Yes & 0.001 & 0.02 & - & - \\
\hline $\mathrm{No}$ & - & - & - & - \\
\hline WHO glioma grades & $\mathrm{NS}$ & - & - & - \\
\hline High grades (IV, III) & - & - & - & - \\
\hline Low grades (II, I) & - & 0.002 & 0.001 & 0.001 \\
\hline $\begin{array}{l}\text { Postoperative } \\
\text { score }\end{array}$ & - & - & - & - \\
\hline$\geq 80$ & - & - & 0.001 & 0.03 \\
\hline $60-70$ & - & - & - & - \\
\hline $10-50$ & - & - & - & - \\
\hline Chemotherapy & - & - & $\mathrm{NS}$ & NS \\
\hline Temozolamide & - & - & - & - \\
\hline $\mathrm{PCV}$ & - & - & - & - \\
\hline
\end{tabular}

Illustrative surgical removal by intraoperative ultrasound: 


\section{Illustrative surgical removal by intraoperative ultrasound:}

Case 1:
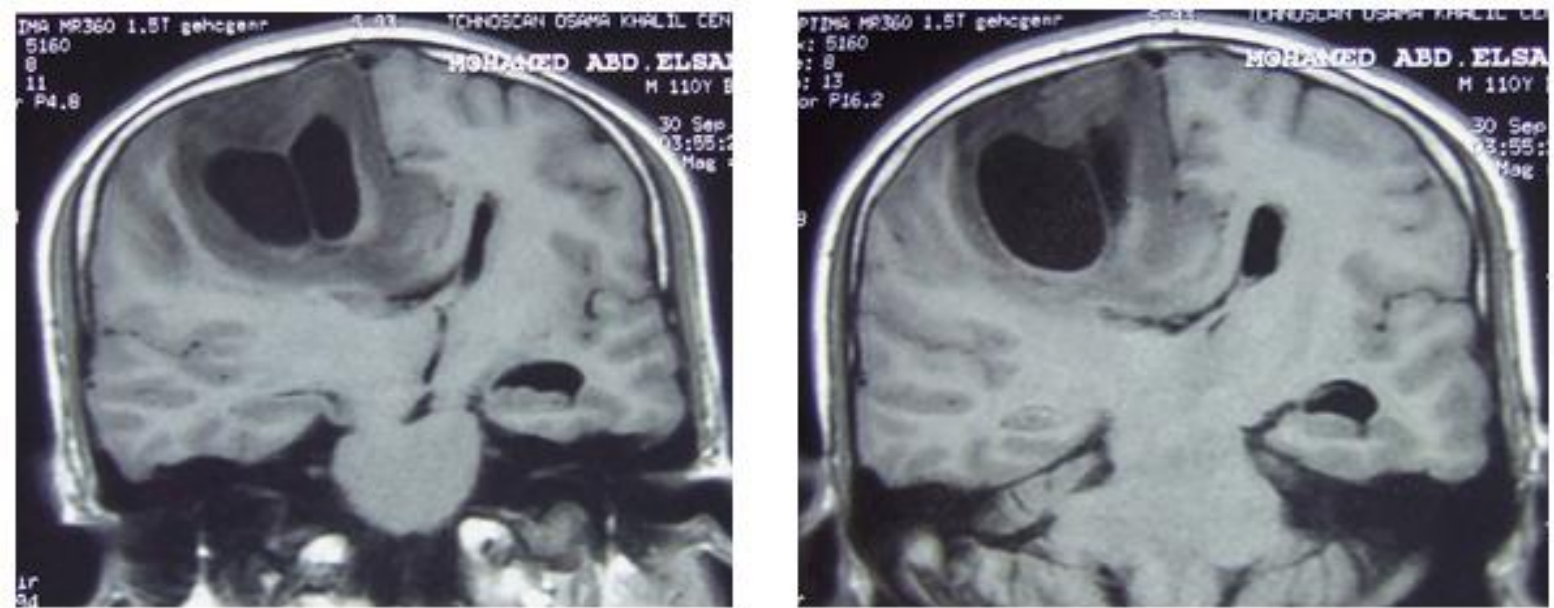

Figure (1): Preoperative $T_{1}$ MRI brain with contrast

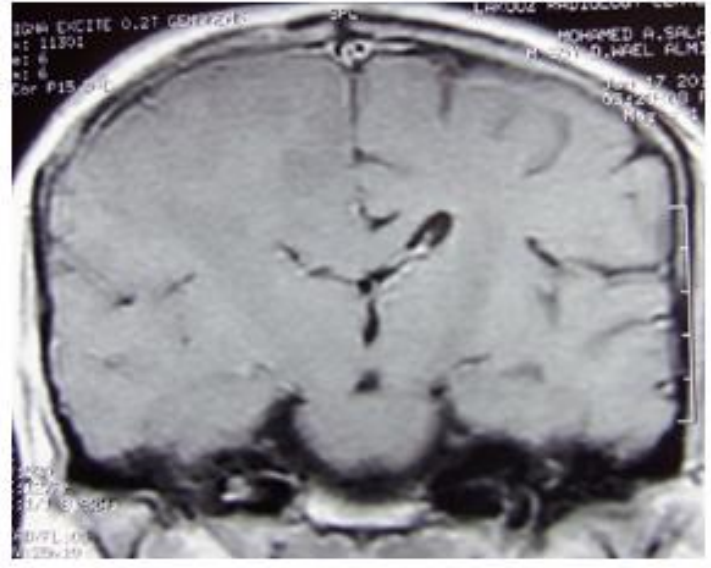

Figure (2): Postoperative $\mathrm{T}_{1} \mathrm{MRI}$ brain with contrast (total excision)

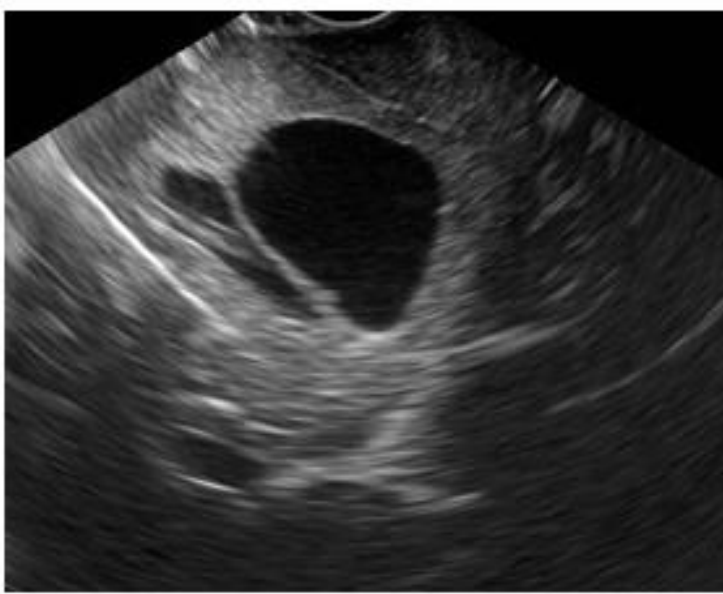

Figure (4): Intraoperative ultrasonography (tumor delineation)

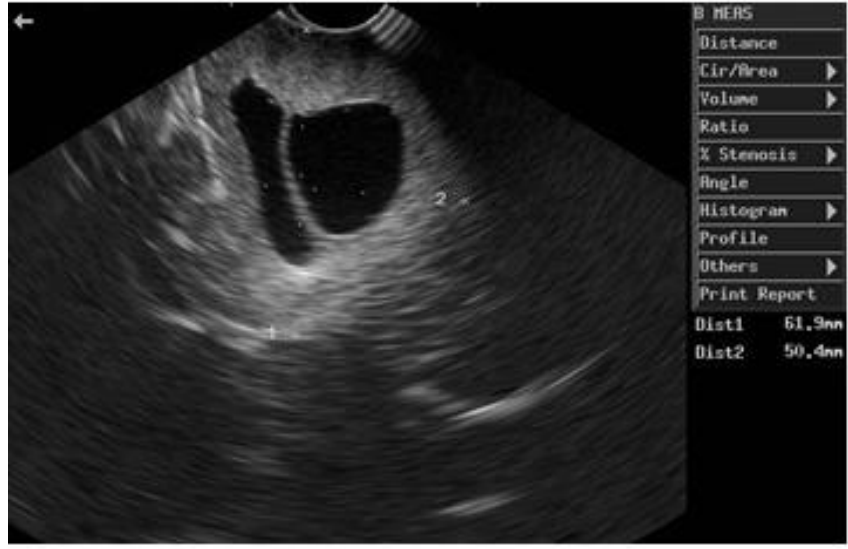

Figure (3): Intraoperative ultrasonography (tumor delineation)

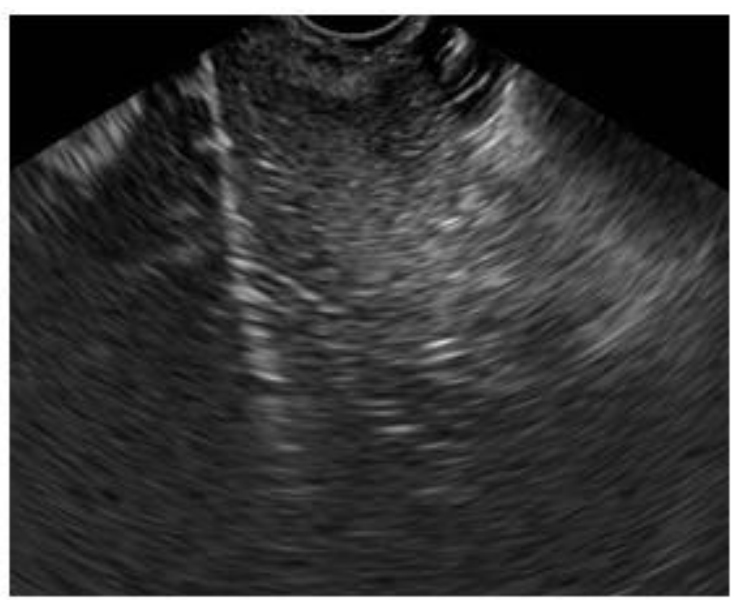

Figure (5): Intraoperative ultrasonography (gross total excision) 


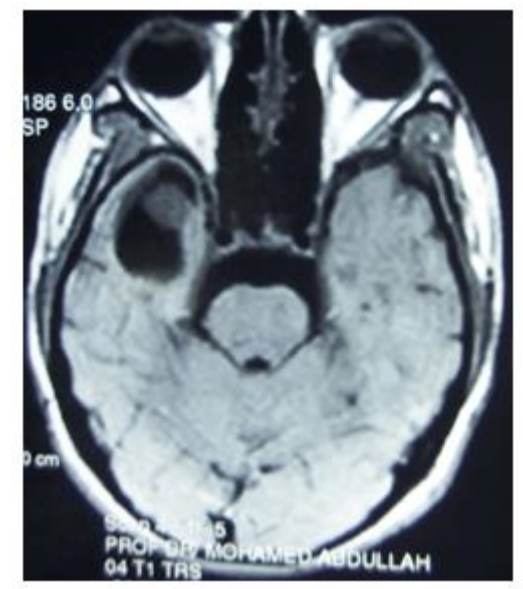

Figure (6): Preoperative $T_{1}$ MRI brain with contrast

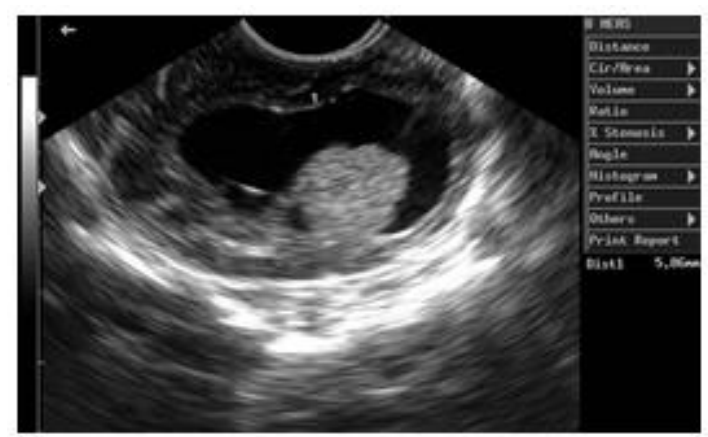

Case 2:

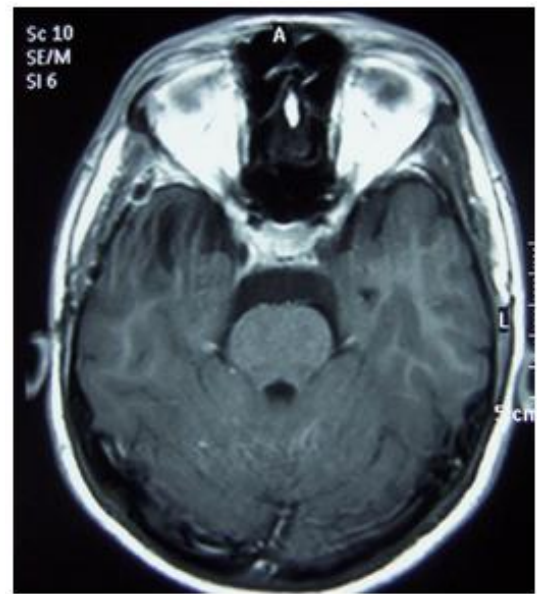

Figure (7): Postoperative $T_{1}$ MRI brain with contrast (total excision)

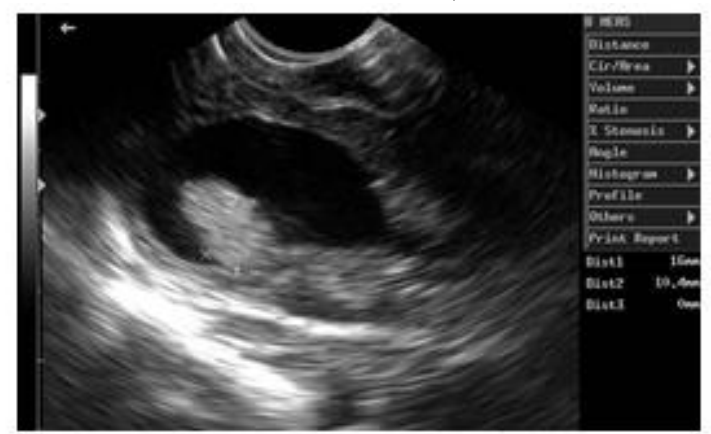

Figure (8): Intraoperative ultrasonography (tumor delineation)
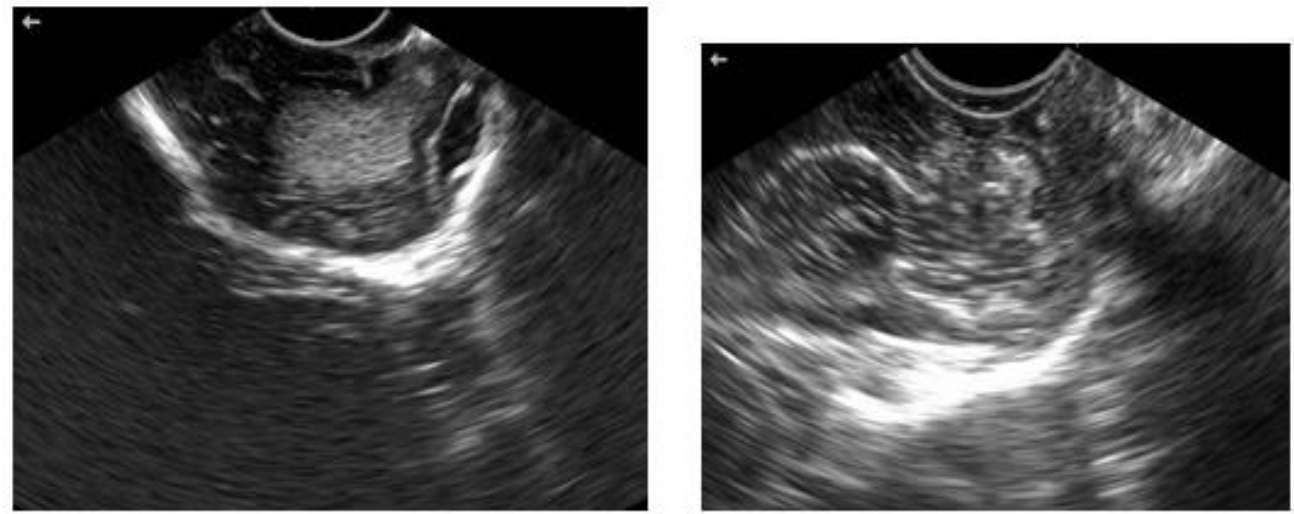

Figure (9): Intraoperative ultrasonography (resection monitoring with total excision)

\section{DISCUSSION}

The successful management of a patient with cerebral glioma depends upon a prompt and accurate diagnosis, careful preoperative planning, skillful tumor removal and good postoperative care.

In this study, the ages of the patients ranged from 17 to 77 years with mean age of 43 years. Suvi et al. ${ }^{(7)}$ studied 331 adult patients with cerebral glioma and reported that the ages ranged from 20 to 69 years with mean of 49.2 years.

The male to female ratio in our study was 1.9:1. There is a male dominance in almost all incidence studies for glial tumors ${ }^{(8)}$ and it was 1.8:1 in Stephen et al. ${ }^{(9)}$ study on cerebral glioma.
In our study, the gradual onset and progressive course were the predominant presentation of our patients $(65.5 \%$ and $78 \%)$ with duration of symptoms ranging from 3 weeks to 8 years.

Nasser et al. ${ }^{(10)}$ reported gradual onset in $88.3 \%$, Tandon et al. ${ }^{(11)}$ reported progressive course in $94 \%$ and Osama et al. ${ }^{(12)}$ reported duration of symptoms of 3 weeks to 10 years.

In this study, the commonest clinical presentation of cerebral gliomas were headache in $78.2 \%$ of the patients, papilloedema in $67.3 \%$, motor weakness in $51 \%$ and epileptic fits in $47.3 \%$ of the patients. 
Younes et al. ${ }^{(13)}$ reported headache in $58.6 \%$, motor weakness in $53.1 \%$ and seizures in $40.7 \%$ as the commonest presentations of cerebral gliomas.

$\operatorname{Van}^{(14)}$ reported papilloedema in $60 \%$ of patients with cerebral gliomas.

In this study, unilateral glioma location was found in $96.4 \%$, with single-lobe involvement in $52.7 \%$. Frontal lobe location was the predominant (in $62.1 \%$ of the patients) and the superficial location in $65.5 \%$.

Suvi et al. ${ }^{(7)}$ reported unilateral location in $95.1 \%$, one lobe location in $68 \%$ and frontal lobe location in $40 \%$.

Houben et al. ${ }^{(15)}$ reported superficial location in $60 \%$ of the patients. Cerebral gliomas as reviewed in a lot of studies tend to grow unilaterally superficially, involving a single lobe with predilection to frontal lobe (according to tissue volume).

In this study, tumor maximal dimension was $\leq 5 \mathrm{~cm}$ in $52.7 \%$ that was $48 \%$ in Stefano et al. ${ }^{(16)}$ study and $57.3 \%$ in Edward et al. ${ }^{(\mathbf{1 7 )}}$ study.

In this study, gross total resection achieved in $18 / 55$ patients $(32.7 \%)$, subtotal in $40 \%$ and partial in $27.3 \%$.

Rajan et al. ${ }^{(18)}$ reported gross total resection in $13.4 \%$, subtotal in $36.6 \%$, partial in $26.8 \%$ and biopsy in $23.2 \%$, while Lighton et al. ${ }^{(19)}$ reported gross total resection in $50.9 \%$, subtotal in $13.8 \%$ and partial in $35 \%$.

The cerebral gliomas in adult patients showed different pathological types and grades with glioblastoma (WHO GIV) was the commonest types in all reviewed studies. Glioblastoma accounted $38.2 \%$ of glioma in our study, $46.5 \%$ in Younes et al. ${ }^{(13)}$ study, $47 \%$ in Suvi et al. ${ }^{(7)}$ study and $72 \%$ in Stefano et al. ${ }^{(16)}$ study.

In this study, IOUS was used in $25 / 55$ operations. The comparison with preoperative MRI and CT showed that the ultrasonography delineated the cystic component, necrotic component, calcification and perilesional oedema in all tumors when present in preoperative investigations with more clearance of these components as there were some septae inside some cysts and not clear in preoperative investigations. Tumor edges were more welldefined in ultrasonographic images $(23 / 25,92 \%)$, while well-defined preoperative investigations were $12 / 25$ (48\%) ( $p<0.05$, significant). These results were matched with a lot of studies as Auer and van Velthoven ${ }^{(20)}$ who reported that ultrasonography gave a more accurate image of the situation than preoperative CT.
Hammoud et al. ${ }^{(21)}$ reported that IOUS provided good delineation of tumor border in $83 \%$ of the primary glioma which is better, than MRI information. These also documented in Koivukangas et al. ${ }^{(22)}$ study.

In this study, there were significant gross total resections with IOUS use which achieved in $52 \%$ of the tumors. These were matched with several studies as Le Roux et al. ${ }^{(23)}$; Bernstein et al. ${ }^{(24)}$ and Jani ${ }^{(25)}$. Wang et al. ${ }^{(26)}$ reported gross total resection in $71.4 \%$.

In this study, there was statistically insignificant difference between the group operated with IOUS use and the group operated without IOUS use regarding operative complications, but there was significant difference between the two groups regarding severe complications in favour of IOUS use. These results were matched with Wang et al. ${ }^{(26)}$ study.

In this study, there were statistically significant correlations between IOUS use and Karnofesky score improvement and independent functional outcome. These results were documented by several studies as Wang et al. ${ }^{(26)}$; Ole et al. ${ }^{(27)}$ and Jakola et al. ${ }^{(28)}$ studies.

The mean survival duration in this study was 13.7 months, median survival was 12.5 months and one-year survival was $69.1 \%$ of the patients.

Ibrahim et al. ${ }^{(29)}$ reported median survival of 13 months, Younes et al. ${ }^{(13)}$ reported one-year survival of $67 \%$ and Wang et al. ${ }^{(30)}$ reported oneyear survival of $69 \%$ of the patients.

In this study, operative mortalities were $3.6 \%$ ( 2 cases) and morbidities were $30.9 \%$ (17 cases). Fadul et al. ${ }^{(31)}$ reported $3.3 \%$ mortalities and $31.7 \%$ morbidities.

Edward et al. ${ }^{(32)}$ reported $5.6 \%$ mortalities and $9.4 \%$ morbidities.

In this study, there were $52.4 \%$ improvement of preoperative morbidities and $76.5 \%$ improvement of postoperative morbidities.

Nobuhiro and Susumu ${ }^{(33)}$ reported 65\% improvement of preoperative morbidities and $75.9 \%$ improvement of postoperative morbidities.

In this study, several factors were found to have a statistically significant better prognosis and matched the data from several studies on adult patients with cerebral gliomas:

1- Young ages $\leq 40$ years.

2- Preoperative Karnofesky scores $\geq 80$.

3- Single-lobe involvement and superficial (cortical) glioma location.

4- Small tumor size $(\leq 5 \mathrm{~cm}$ maximal dimension). 
5- Gross total resection.

6- Low-grade gliomas.

7- Postoperative Karnofesky score $\geq 80$.

8- Intraoperative ultrasonography use $\mathrm{se}^{(26,28,34,35)}$. $(13,29,36,37,38,39,40,41,42,43)$

In this study, the patient sex (male or female) did not affect the prognosis and this was agreed in several studies as Younes et al. ${ }^{(13)}$, Ibrahim et al. ${ }^{(29)}$, Chaiyot and Yot ${ }^{(39)}$ studies.

In this study, there were no significant differences between the patient group treated by tenozolamide chemotherapy and the group treated by PCV chemotherapy regarding survival, progression-free survival and tumor regression response. These results were documented in metaanalysis of Martin et al. ${ }^{(44)}$ and Ben ${ }^{(45)}$ and study of Siow et al. ${ }^{(46)}$.

In this study, the regression response of residual glioma (after surgery) to radiochemotherapy was $6 / 22$ patients $(27.3 \%)$, to radiotherapy without chemotherapy was $6 / 12$ patients (50\%) and overall regression was $12 / 34$ patients $(35.3 \%)$.

Patients receiving radiochemotherapy were mostly with high-grade gliomas and patients receiving radiotherapy without chemotherapy were mostly with low-grade glioma.

Lunsford et al. $^{(47)}$ reported regression response to incompletely resected low-grade gliomas after radiotherapy (46\%) and Glenn et al. $^{(\mathbf{4 8 )}}$ found the response $52 \%$.

Martin et al. ${ }^{(44)}$ found the regression response of high-grade gliomas to radiochemotherapy varied between studies from $13.6 \%$ to $35 \%$.

\section{CONCLUSION}

Cerebral glioma is a devastating disease especially high grades and extensive researches still in need for approaching the solution.

In our study, the prognostic factors of cerebral gliomas were: young age, high preoperative Karnofesky score $\geq 80$, single-lobe location of glioma, superficial location, small tumor size $\leq 5 \mathrm{~cm}$, gross total resection, intraoperative ultrasonography use, low-grade glioma and high postoperative Karnofesky scores $\geq 80$.

\section{REFERENCES}

1- Jeremic B, Milicic B, Grujicic D, et al. Multivariate analysis of clinical prognostic factors in patients with glioma treated with a combined modality approach. J Cancer Res Clin Oncol 2003; 129(8): 477-484.

2- Vernooji M, Ikram A, Tanghe HL, et al. Treatment options for gliomas of the central nervous system. N Engl J Med 2007; 357: 1821-1828.
3- Unsgaard G, Gronningsaeter A, Ommedal S, et al. Brain operations guided by real time twodimensional ultrasound: New possibilities as a result of improved image quality. Neurosurgery 2002; 51: 402-411.

4- Gudinaviciene I, Pranys D and Juozaityte E. Impact of morphology and biology on the prognosis of patients with gliomas. Medicina (Kaunas) 2004; 40: 112-120.

5- Karnofesky DA and Burchenal J. The clinical evaluation of chemotherapeutic agents in cancer. In: Macleod CM, editor. Evaluation of chemotherapeutic agents. New York: Columbia University Press 1949; 191-205.

6- Lieberman AN, Foo SH, Raasohopf J, et al. Longterm survival among patients with mliangnat brain tumors. Neurosurgery 1982; 10: 450-453.

7- Suvi L, Riitta M, Tiina S, et al. Incidence of gliomas by anatomic location. J Neuro-Oncology 2007; 9: 319-325.

8- Bekir T, Lutfi S, Omur G, et al. Efficacy of clinical prognostic factors on survival in patients with glioblastoma. Turkish Neurosurgery 2010; 20(2): 117-125.

9- Stephen M, Robert E, David F, et al. Resection of parietal lobe gliomas: Incidence and evolution of neurological deficits. J Neurosurg 2005; 103: 1010-1017.

10- Nasser MF, Khairy S, Shawky EH, et al. Surgical aspects of gliomas and response to treatment. Thesis of MD Degree in Neurosurgery, Cairo University 1990.

11- Tandon PN, Mahapatra AK and Khosla A. Epileptic seizures in supratentorial glioma. Neurology India 2001; 49(1): 55-90.

12- Osama ZM, Nabhan TK, Wafaa HE, et al. Management and radioresponse of brain gliomas. Thesis of Master Degree in General Surgery, Cairo University 1995.

13- Younes R, Mahmoodreza K, Alireza S, et al. The clinical trend and prognosis of patients with brain glioma. Iran J Pathol 2010; 5(2): 77-82.

14- Van HC. Absence of papilloedema in cerebral gliomas. Journal of Neurology, Neurosurgery and Psychiatry; 38: 931-933.

15- Houben M, Abnen, Teepen J, et al. Stable incidence of childhood and adult glioma in Netherlands 1989-2003. Acta Oncologica 2006; 45: 272-279.

16- Stefano M, Umberto R, Riccardo S, et al. Patterns of practice and survival in a retrospective analysis of 1722 adult astrocytoma patients treated between 1985 and 2001 ini 12 Italian radiation oncology centers. Int. J. Radiation Oncology Biol. Phys. 2006; 65(3): 788-799.

17- Edward F, Chang M, Justin S, et al. Preoperative prognostic classification system for hemispheric glioma in adulots. J Neurosurg 2008; 109: 817824.

18- Rajan B, Pickuth D, Ashley S, et al. The management of histologically unverified 
presumed cerebral gliomas with radiotherapy. Int J Radiat Oncol Biol Phys 1994; 28: 405-413.

19- Lighton C, Fisher B, Bauman G, et al. Supratentorial low grade glioma in adults. J Clin Oncol 1997; 15(4): 1294-1301.

20-Auer LM and Van Velthoven V. Intraoperative ultrasonography imaging. Acta Neurochir (Wien) 1990; 104: 84-95.

21- Hammoud MA, Ligon BL, Elsouk R, et al. Use of intraoperative ultrasound for localizing tumors and determining the extent of resection: A comparative study with magnetic resonance imaging. J Neurosurg 1996; 84: 737-741.

22- Koivukangas J, Louhisalmi Y, Alakuijala J, et al. Ultrasound controlled neuronavigator-guided brain surgery. J Neurosurg 1993; 79: 36-42.

23- Le Roux PD, Berger MS, Wang K, et al. Lowgrade gliomas: Comparison of intraoperative ultrasound characteristics with preoperative imaging studies. J Neuro-Oncol 1992; 13: 189198.

24- Bernstein EM, Gulati S, Solheim O, et al. Intraoperative ultrasound neuronavigation: Impact on therapeutic strategies, extent of resection and clinical outcome. Neurosurgery 2010; 67: 251264.

25- Jani K. Intraoperative imaging-guided delineation and localization of regions of surgical interest. Acta Univ Out D 2012; 114: 71-100.

26- Wang J, Liu X, Hou WH, et al. The relationship between intraoperative ultrasonography and pathological grade in cerebral glioma. Journal of International Medical Research 2008; 36: 14261434.

27-Ole S, Tormod S, Asgeir S, et al. Ultrasoundguided operations in unselected glioma. Acta Neurochirurgica 2010; 152: 1873-1886.

28- Jakola AS, Unsgard G and Solheim O. Quality of life in patients with intracranial glioma: The impact of modern image-guided surgery. J Neurosurg 2011; 114(6): 1622-1630.

29- Ibrahim A, Nawal M, Mustafa A, et al. Transition from $2 \mathrm{D}$ conventional to $3 \mathrm{D}$ conformal radiation therapy in patients with brain gliomas: Clinical outcome. Journal of the Egyptian Nat. Cancer Inst. 2009; 21(2): 133-138.

30-Wang J, Liu X, Ba YM, et al. Effect of sonography-guided cerebral glioma surgery on survival time. J Ultrasound Med 2012; 31(5): 757-762.

31- Fadul C, Wood J, Thaler H, et al. Morbidity and mortality of craniotomy for excision of supratentorial gliomas. Neurology 1988; 38(9): 1374.

32- Edward G, Jeffrey $H$ and Wisoff S. Prospective clinical trials of intracranial low grade glioma in adults and children. Neuro-Oncology 2003; 5: 153-160.

33- Nobuhiro M and Susumu M. Surgical treatment of glioma: Extent of resection applying functional neurosurgery. Neurol Med Chir (Tokyo) 2010; 50: 270-276.

34- Stummer W, Pichlmeier U, Meinel T, et al. Fluorescence-guided surgery for resection of malignant glioma. Lancet Oncol 2006; 7(5): 392401.

35-McGirt MJ, Chaichana KL, Gathinji M, et al. Independent association of extent of resection with survival in patients with malignant brain astrocytoma. J Neurosurg 2009; 110(1): 156-162.

36- Stupp R, Janzer RC, Hegi ME, et al. Prognostic factors for low grade gliomas. Semin Oncol 2003; 30: 23-28.

37- Yeh SA, Ho JT, Lui CC, et al. Treatment outcomes and prognostic factors in patients with supratentorial low grade gliomas. British Journal of Radiology 2005; 78: 230-235.

38- Faramarz A, Abbass A, Mohamed R, et al. Evaluation of the prognostic factors effective on the outcome of patients with cerebral glioma. Official Journal of the World Federation of the Neurosurgical Societies 2010; 73(2): 129-134.

39- Chaiyot $\mathrm{S}$ and Yot N. A multivariate analysis of patients with glioma: Treatment outcome and prognostic factor for survival. J Med Assoc Thai 2008; 91(4): 491-496.

40- Sanai N and Mitchel S. Glioma extent of resection and its impact on patient outcome. Neurosurgery 2008; 62(4): 753-766.

41-Shou L, Xiao-Guang Q, Bao-Shi C, et al. Prognostic factors influencing clinical outcomes of glioblastoma multiforme. Chinese Medical Journal 2009; 122(11): 1245-1249.

42- Edward F, Chang E, Aaron C, et al. Prognostic scoring system for cerebral glioma. J Neurosurg 2009; 111: 203-210.

43- Raymond L, Margaretta P, Karla S, et al. Quality of life in adults with brain tumors. NeuroOncology 2009; 11: 331-339.

44- Martin J, Van den Bent T, Monika E, et al. Recent development in use of chemotherapy in brain tumors. European Journal of Cancer 2006; 42: 582-588.

45- Ben AW. Treatment options for glioblastoma and other gliomas: Musella Foundation 2011; 117122.

46- Siow ML, Brada M, Gabe R, et al. A randomized trial of temozolamide versus PCV chemotherapy for malignant glioma. National Cancer Research Institute (NCRI), UK, BR 2008; 12.

47- Lunsford LD, Somaza S, Kondziolka D, et al. Survival after stereotactic biopsy and radiation of cerebral non-neoplastic non-pilocytic astrocytoma. J Neurosurg 1995; 82: 523-529.

48- Glenn B, Peter P, David M, et al. Low-grade glioma: A measuring radiographic response to radiotherapy. Can. J. Neurol. Sci. 1999; 26: 1822. 


\section{طرق علاج الأورام المخية الدبقية \\ وائل عبد الرحمن على المسلمى، د/ حمدى مرسى فرحات، دالد / طارق حسن علد علد البارى،

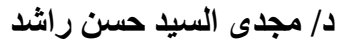

قسم جر احة المخ و الأعصابــ كلية الطبــ جامعة الزقازيق

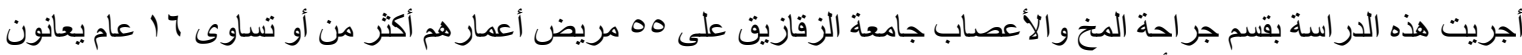

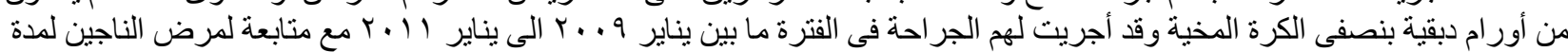

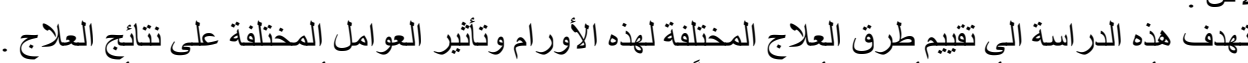

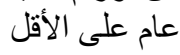

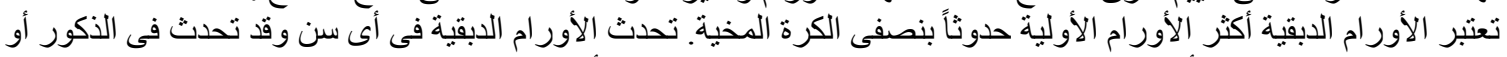

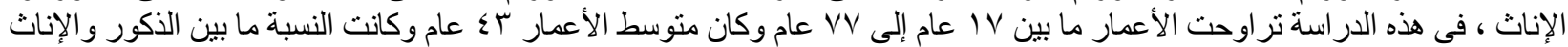

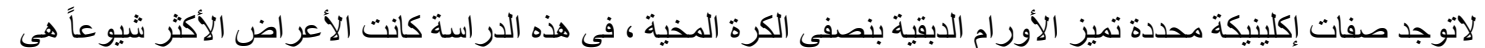

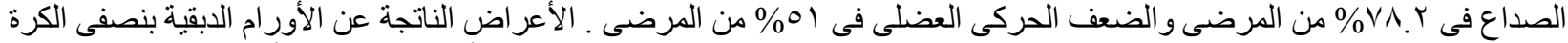

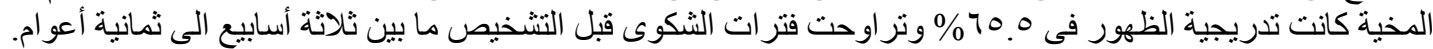

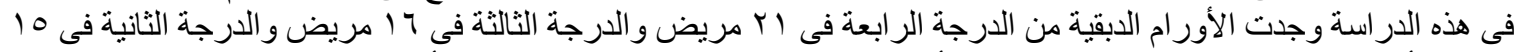

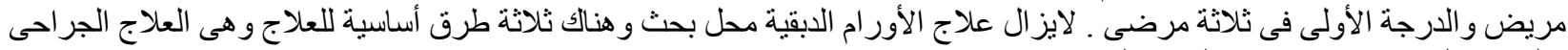

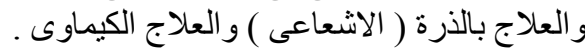

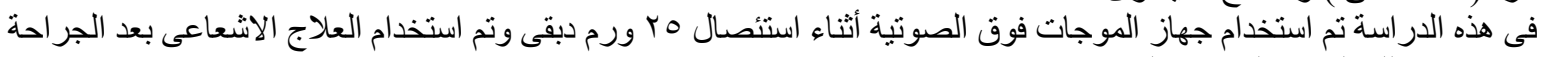

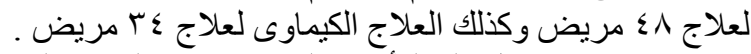

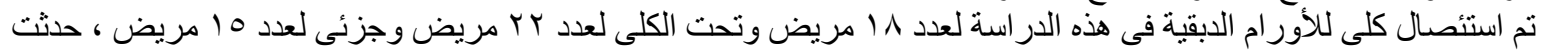

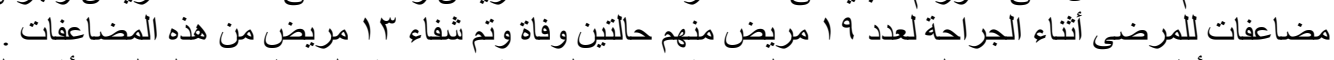

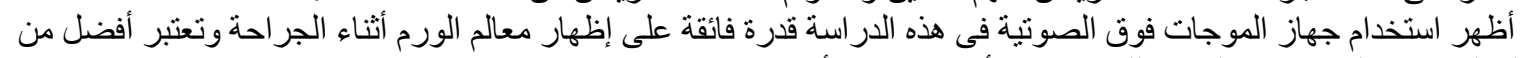

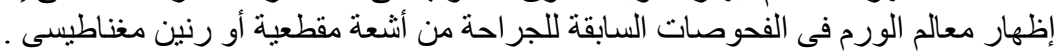

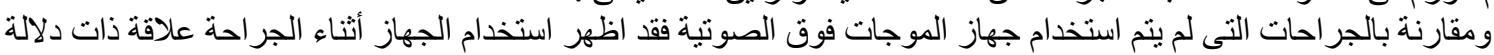

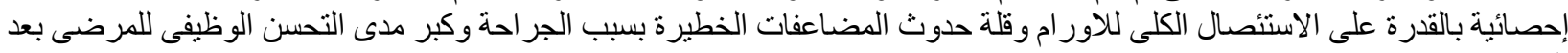

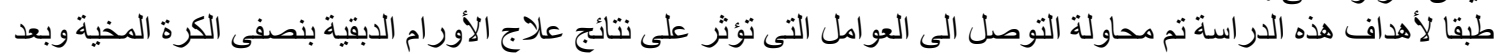

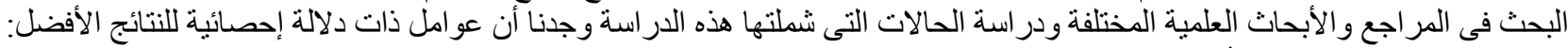

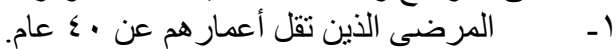

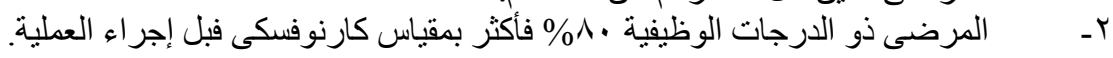

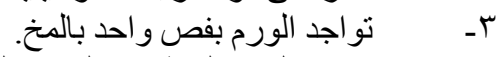

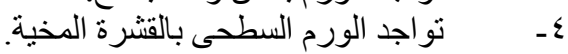

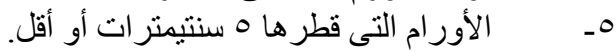

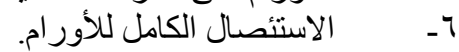

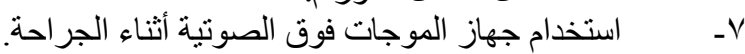

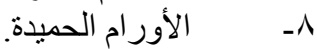

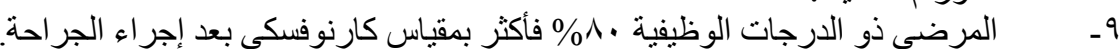

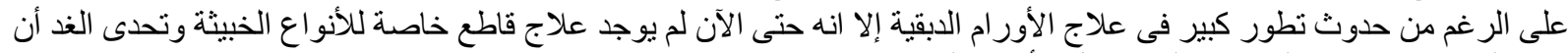
نحاول و إن لم نستطيع كثف الغموض القائم حول الأورام الدبقية . 